\title{
Imaginarios urbanos y representaciones culturales en la historia del sector antiguo de Tunja (1968 - 1979)
}

\author{
Urban imaginaries and cultural representations in the history of the ancient sector of Tunja
} $(1968$ - 1979)

DOI: https://doi.org/10.21803/penamer.14.27.339

\section{Leonardo Enrique Osorio Salazar}

https://orcid.org/0000-0003-4896-5437
¿Cómo citar este artículo?

Osorio, L. (2021). Imaginarios urbanos y representaciones culturales en la historia del sector antiguo de Tunja (1968-1979). Pensamiento Americano, 14(27), 181-194. DOI: https://doi. org/10.21803/penamer.14.27.339

\section{Resumen}

Objetivo: presentar una reflexión sobre las relaciones entre imaginarios urbanos y representaciones culturales referidas al espacio urbano heredado del sector antiguo de Tunja; ciudad histórica, patrimonial y cultural representativa de la Arquitectura y la sociedad del siglo XVI, que ha prevalecido hasta la actualidad en Colombia. Para tal fin se hace énfasis en el periodo comprendido entre 1968 y 1979, en el cual se expresaron anhelos políticos, académicos y culturales en el contexto de una modernización que estuvo en tensión constante por las perspectivas de cambio y prevalencias que surgieron de los intereses de diferentes sectores de la sociedad y que determinaron expresiones de cambios materiales, de uso del espacio urbano heredado, y desuso de la arquitectura doméstica tradicional. Método o metodología: El método de abordaje se hizo desde un enfoque cualitativo e inductivo, con el análisis reflexión y síntesis explicativa de fuentes primarias, historiográficas y materiales presentes en la arquitectura y el urbanismo de la ciudad. Resultados y conclusiones: El resultado de la investigación presenta los principales temas de debate, así como los actores y fuerzas urbanas que incidieron en la significación histórica y cultural de esta ciudad, y cuyo cuestionamiento permite explicar los principales significados que tuvieron las representaciones materiales en la conformación de una memoria urbana, artística y cultural, que incidió en la distinción de una identidad propia, en el contexto latinoamericano.

Palabras clave: Percepciones; Representaciones; Tunja; Cambios; Prevalencias; Identidad.

\begin{abstract}
Objective: to present a reflection on the relationships between urban imaginaries and cultural representations referring to the urban space inherited from the old sector of Tunja; Historical, patrimonial and cultural city representative of the Architecture and the society of the XVI century, that has prevailed until the present time in Colombia. To this end, an emphasis is placed on the period between 1968 and 1979, in which political, academic and cultural desires were expressed in the context of a modernization that was in constant tension due to the perspectives of change and prevalences that arose from the interests of different sectors of society and that determined expressions of material changes, use of inherited urban space, and disuse of traditional domestic architecture.

Method or methodology: The approach method was made from a qualitative and inductive approach, with the analysis, reflection and explanatory synthesis of primary, historiographic and material sources
\end{abstract}


present in the architecture and urban planning of the city. Results and conclusions: The result of the research presents the main topics of debate, as well as the actors and urban forces that influenced the historical and cultural significance of this city, and whose questioning allows to explain the main meanings that material representations had in the conformation of an urban, artistic and cultural memory, which influenced the distinction of its own identity, in the Latin American context.

Keywords: Perceptions; Representations; Tunja; Changes; Prevalences; Identity.

\section{Resumo}

a

Palavras chave: a

\section{Perfiles}

Arquitecto, Universidad Santo Tomás; Magister en Historia, Universidad Pedagógica y Tecnológica de Colombia, U.P.T.C.; Doctor en Historia, Universidad Pedagógica y Tecnológica de Colombia U.P.T.C. Docente Programa de Arquitectura Leonardo Enrique Osorio Salazar Universidad Santo Tomás seccional Tunja, Colombia. Correo: leonardo.osorio@ usantoto.edu.co 


\section{Introducción}

El presente trabajo, hace una reflexión con base en la investigación marco: el sector Antiguo de Tunja. Historia Urbana y Patrimonio Material (1951 - 1979), que se adelantó en los años 2014 a 2020, como parte de los estudios para optar por el título de Doctor en Historia, adelantados en la Universidad Pedagógica y Tecnológica de Colombia U.P.T.C. en la facultad de educación, en el doctorado en Historia; así como de las actividades de investigación, adelantadas en el programa de Arquitectura de la Universidad Santo Tomás seccional Tunja en el periodo comprendido entre 2019 y 2020 , en el marco del estudio sobre las relaciones entre arquitectura, urbanismo, historia y cultura, de una ciudad como Tunja, capital del departamento de Boyacá en Colombia, que representa un importante legado histórico y patrimonial presente en su espacio urbano heredado desde el siglo XVI y del cual este artículo hace parte. En este sentido, el objetivo central propone profundizar en la categoría de los imaginarios urbanos y representaciones culturales y determinar su incidencia como medio de análisis en la historia del Sector Antiguo de Tunja en los años comprendidos entre 1968 y 1979. En este sentido, se afirma que es posible comprender las percepciones de actores testimoniales, a través del estudio de la composición de las representaciones urbanas y culturales, presentes en diferentes imágenes que conforman los archivos y relatos que hacen parte de la historia urbana del sector antiguo de la ciudad, y que a partir de allí, se puede a su vez, hacer una recomposición histórica con la triangulación y contraste de estas imágenes síntesis para dar un sentido a la historia urbana del lugar.

Para este fin, los conceptos sobre la ciudad y las imágenes que la representan, son el sustrato conceptual para adelantar el estudio del sector antiguo de Tunja de su historia y significados culturales en el tiempo, para comprender las percepciones y los sentidos que los actores principales que incidieron en ella y en su tejido cultural, proyectaron como un anhelo que en el periodo comprendido entre 1968 a 1979, caracterizó el ideario social, por conocer un pasado ya superado, conformado por un orden colonial y de un estado nacional que expresó en las representaciones arquitectónicas y urbanas del sector antiguo de la ciudad, su ideal de nación y el cual, para la segunda mitad del siglo XX, contrasto con una modernización que dispuso sobre la ciudad heredada, nuevos sentidos motivados por un sentido utilitario del lugar.

\section{DESARROLLO DEL ARTÍCULO}

\section{El paradigma de los centros Históricos}

Un primer problema es el relacionado con los Centros Históricos como objeto de estudio. Como resultado de la investigación de referencia, se determinó que su análisis desde las dicotomías: realidad - concepto y tiempo - espacio (Carrión, 2019, p. 29), permitía establecer una visión contextual de representaciones que se enriquece al relacionarlas con dos discusiones a saber: sobre los significados de estas centralidades en el tiempo y, en segundo lugar, sobre los momentos de cambios de significación que caracterizaron su devenir histórico en el siglo XX. En los dos casos, se rastrearon las representaciones en cartas internacionales, documentos historiográficos relacionados, y experiencias académicas, que han permitido comprender aspectos históricos sobre su génesis, desarrollo, y finalmente sobre cómo llegaron a ser en múltiples casos políticas públicas de protección conservación y de gestión.

El análisis y categorización de la información permitió a su vez, definir tres momentos paradigmáticos de significación cultural que surgen del estudio de los imaginarios urbanos internacionales en el siglo XX. El primer momento ubica los orígenes de la discusión sobre la importancia de las centralidades históricas en el contexto internacional, en el marco de un ideario de emergencia que se originó en el mundo, por los cambios en la delimitación de las morfologías históricas de las ciudades y las pérdidas materiales y humanas ocasionadas por una Guerra Mundial (1910-1919). Aquí, se determinaron como

Pensamiento Americano Vol. 14 - No. 27 - p.p. 181-194 • 2021 • Enero - Junio • Corporación Universitaria Americana · Barranquilla, Colombia · ISSN-e: 2745-1402 http://publicaciones.americana.edu.co/index.php/pensamientoamericano/index 
factores característicos del período, las tensiones urbanas que surgieron entre diferentes actores políticos nacionales, cuyo interés principal fue legitimarse en el escenario geopolítico internacional; situación que tuvo como consecuencia directa el establecimiento de un nuevo orden mundial diferente al que existió en el siglo XIX.

Igualmente, importantes fueron las tensiones y discusiones sobre los lineamientos conceptuales para recomponer el espacio urbano afectado por la guerra, cuyas perspectivas de abordaje, respondieron a los intereses de grupos vanguardistas que fueron incentivados de manera activa, por las fuerzas de cambio y de una modernización signadas por el estilo internacional en arquitectura y que tuvo una de sus principales expresiones en los Congresos Internacionales de Arquitectura Moderna (CIAM). En contraste con este imaginario de cambio, estuvo una corriente de pensamiento que dispuso definir y legitimar las principales expresiones monumentales del pasado y de las expresiones simbólicas heredadas en el espacio urbano de las ciudades, cuya síntesis se evidencia en la carta de Atenas (1930), que representó una toma de conciencia sobre el reconocimiento del monumento (parte histórica) y la búsqueda de la conservación de los valores históricos y estéticos de las ciudades portadoras de esta herencia cultural, frente a las añoranzas y la conciencia sobre la importancia de los recuerdos y las memorias que conjugaba un pasado monumental, que estaba en peligro de desaparecer y que permitió en el tiempo, matizar la primacía del bien común frente al bien individual, ubicándose como un punto de inflexión para la toma de conciencia de estos bienes culturales como herencia de la humanidad (Carta de Atenas, 1933).

El establecimiento de una percepción entre lo nuevo y lo tradicional estuvo presente en este momento. El interés común en virtud de los valores estéticos y de una imagen que favoreció a los monumentos históricos como valores heredados, fue un factor distintivo que primó los significados materiales de los monumentos (Carta de Atenas, 1933), así como las indicaciones intencionadas que entrañan sus significaciones para la sociedad (Bonta, 1973). En este periodo, los principales significados de las centralidades históricas heredadas de siglos anteriores, se caracterizaron por la importancia histórica que adquirieron diferentes edificaciones con valor monumental y por el interés cultural que contenían, marcando como característica central el reconocimiento de unidades simbólicas particulares, dignas de ser preservadas como expresión de políticas de la memoria y del recuerdo, que orientaron una legitimación y prevalencia política y cultural que se encontraba en una crisis de significación.

Un segundo momento se ubica en el periodo de 1939 a 1945, en el contexto de la Segunda Guerra Mundial que matizó la amenaza y peligro de la pérdida de monumentos históricos y otras herencias tangibles e intangibles del pasado, y la década de 1960 cuando se experimentó un cambio en la significación de elementos aislados hacia una idea de conjunto con valores históricos y culturales motivada por organismos que surgieron como una estrategia multinacional, para hacer frente a las fuerzas de cambio y pérdida de elementos con una importancia histórica para la humanidad lideradas por la UNESCO (1945) e ICOMOS (1964). Este, fue un periodo de zozobra internacional por los avatares de la guerra y por las tensiones que surgieron entre el desarrollo de la técnica y las narrativas de avance y desarrollo tecnológico que se expresaron y asociaron con una idea de cambio, que contrastaron con los intereses de conservación material de grupos urbanos y culturales de intelectuales, profesionales y académicos, que se manifestaron frente a la amenaza que constituyó el avance de la guerra y la destrucción de sitios de interés histórico (Convención de la Haya, 1954). Las discusiones especializadas sobre los significados de los elementos monumentales concluyeron en un anhelo de conservación de elementos monumentales y de los conjuntos históricos, que se manifestó en la definición de centros monumentales descritos en el numeral C, de la carta de referencia así: "Los centros que comprendan un número considerable de bienes culturales definidos en los apartados a. y b., que se

Pensamiento Americano Vol. 14 - No. 27 - p.p. 181-194 • 2021 • Enero - Junio · Corporación Universitaria Americana · Barranquilla, Colombia • ISSN-e: 2745 -1402 http://publicaciones.americana.edu.co/index.php/pensamientoamericano/index 
denominan «centros monumentales»" (Convención de la Haya, 1954).

La declaratoria que se hizo del Centro Histórico de la Ciudad de Quito, (1964-1967), fue a su vez, un referente canónico de cambio que ha permitido definir un tercer momento de especialización, caracterizado por el cambio en el imaginario cultural, que se sigue en las recomendaciones para el establecimiento de mecanismos de acción que se siguió por las declaratorias emitidas por la UNESCO, sobre bienes de interés cultural, y por el establecimiento de políticas de catalogación, planeación e intervención, que motivaron una nueva manera de concebir a estas centralidades y que encontró en la categoría de los centros históricos su principal instrumento de catalogación. Finalmente se observa que, durante la década de 1970, se cristalizó la especialización para el manejo de los bienes históricos portadores de una memoria material de interés universal, que se evidencia en importantes acciones como la emanada por la Convención para la protección del patrimonio mundial ratificada en 1977, y en la cual se vincularon los factores económicos como nuevos elementos que afectan la persistencia de los valores heredados y que enriquecieron la discusión, frente a la continuidad de los conjuntos como unidades propias de significación patrimonial. En la Carta de Washington (1987), se desarrolló un escenario epistemológico de significación, con una visión integradora que vinculó diferentes zonas poblacionales de los centros urbanos con carácter histórico. En suma, el estudio de estos contextos permite reconocer en sus significados, la importancia del espacio urbano heredado y su significación desde referentes históricos, políticos y culturales que han permitido la conformación de un campo propio que actualmente estudia las relaciones entre los componentes: espacial, temporal y patrimonial (Carrión, 2019, p. 29), y que complementan el marco conceptual de análisis urbano y patrimonial de esta reflexión.

\section{El contexto Latinoamericano.}

Desde la década de 1960, en el contexto latinoa- mericano se matizaron las bases para la constitución de un campo de especialización relacionado con los estudios de la ciudad, que tuvieron como consecuencia directa, la manifestación de una conciencia sobre la importancia del presente y de cómo actuar en él a la luz de interrogantes que se podían plantear al pasado, (Romero, 1975). El interés por las ciudades coloniales, su desarrollo urbano y la incorporación de mecanismos de planeación, fueron ambientes propicios para la constitución de un pensamiento que se caracterizó por representar expresiones que tuvieron por objetivo final, la búsqueda de temas propios de estudio que permitieran comprender las características diferenciadoras que conforman al espacio urbano latinoamericano.

La ciudad fue un tema de discusión en academias y centros de estudios, que expresaron en su producción bibliográfica, diferentes narrativas culturales en las cuales se representó un interés naciente por determinar una identidad propia en el marco del contexto regional, que permitiera una diferenciación del contexto internacional europeo. En este sentido, fueron actores académicos pioneros en estas discusiones: Jorge Enrique Hardoy con los títulos: ciudades precolombinas (1964), y el proceso de urbanización en América Latina (1974); en conjunto con José Luis Romero y el estudio Latinoamérica: las ciudades y las ideas (1975). En estos trabajos se presentaron síntesis sobre el desarrollo urbano de la ciudad latinoamericana, a la vez que se indicaron temas de estudio sobre los orígenes, desarrollo urbano, características poblacionales, además de formas de crecimiento y expansión, que motivarían los estudios adelantados por otros académicos y profesionales de la historia, la arquitectura y el urbanismo. En efecto, en títulos como América Latina en su Arquitectura. De Roberto Segre (1975), y Arquitectura y urbanismo en Iberoamérica de Ramón Gutiérrez, (1984), se insinuaron las pautas que permitieron comprender las particularidades de la región latinoamericana y la importancia de interrogar al pasado para comprender los orígenes y el desarrollo de problemas poblacionales, de desarrollo urbano, de miseria y de economías precarias, que aquejan al

Pensamiento Americano Vol. 14 - No. 27 - p.p. 181-194 • 2021 • Enero - Junio • Corporación Universitaria Americana • Barranquilla, Colombia • ISSN-e: 2745-1402 http://publicaciones.americana.edu.co/index.php/pensamientoamericano/index 
continente americano en el presente de 1970.

Colombia hizo parte de este ambiente de pensamiento a través de Universidades e institutos de estudio, que prestaron especial atención a la actualidad de los sectores antiguos de la ciudad heredada de siglos anteriores. En efecto, la creación de la facultad de Arquitectura y Bellas Artes de la Universidad Nacional de Colombia (1939), de la facultad de Arquitectura de la Universidad Javeriana (1947) y del programa de Arquitectura de la Universidad de los Andes (1984), permitió la expresión y el desarrollo de discusiones sobre estos sectores de la ciudad, situación que tendría una importante incidencia en Tunja a través de los trabajos académicos de Santiago Sebastián (1966) y el título la ornamentación en el Nuevo Reino de Granada, el Inventario de bienes históricos de Tunja, liderado por el Arquitecto Alberto Corradine (1973) y el instituto geográfico Agustin Codazzi y de los trabajos dirigidos por Jaime Salcedo dentro de los que se destaca para efectos de esta investigación el de Conservación del centro histórico de Jorge Ayala Coll (1977).

Las descripciones que hizo Santiago Sebastián a través del título: la ornamentación en el Nuevo Reino de Granada, representan el imaginario del arte Tunjano visible en la ornamentación de iglesias con motivos platerescos representados en sus techumbres, las pieles de muros y de los pilares labrados en madera, además de una arquitectura domestica con importantes expresiones de pintura mural, presentes en edificaciones como la perteneciente al fundador de la Ciudad Don Gonzalo Suarez Rendón, del escribano don Juan de Vargas y de aquella que en el imaginario popular perteneció a Don Juan de Castellanos, resaltando en las dos primeras sus motivos naturales y en la segunda sus geometrías, con lo cual presentó al mundo académico su importancia, y a su vez matizó a este arte como un aspecto particular de la ciudad:

Frente a las decoraciones de las casas de Juan de Vargas y de Suárez Rendón, evocadoras del repertorio ornamental y simbólico del manierismo, estas destacan por la presencia de flora americana. La representación de la fauna, salvo detalles de tipo naturista, responde a las exigencias simbólicas propias del conjunto religioso. Es obra sin pretensiones de calidad, meramente artesanal, pero el naturalismo que se observa en la representación de elementos decorativos tomados del medio ambiente americano habla de un acusado barroquismo (Sebastián, 1966, p. 121).

En este mismo periodo el estudio: Inventario de bienes históricos de Tunja, que dirigió el Arquitecto Alberto Corradine a través de la división de inventarios de patrimonio cultural de la Universidad Nacional de Colombia de la facultad de Bellas Artes, centró su atención en el sector antiguo de Tunja, con el estudio de 183 edificaciones. En este trabajo se hizo énfasis en la historia, cualidades y estado material de diferentes edificaciones, expresando un cuadro tipológico que se caracterizó por la segregación de viviendas, y de un proceso que modificó las estructuras formales concéntricas iniciales de estas edificaciones. El análisis realizado en este estudio permite comprender según las descripciones de las fichas de inventario y de catalogación, que para 1970, estas se mantenían en un $62 \%$ representadas en 114 unidades prediales, frente a un $22 \%$ de viviendas con nuevas estructuras y agrupaciones fragmentadas representadas en 42 nuevas unidades prediales con una estructura compuesta, en conjunto con un $6 \%$ de viviendas con estructuras formales lineales claramente definidas, adelantadas en los siglos XIX y XX, en su mayoría con expresiones que se ejemplifican a continuación. (Ver figura 1.)

De este estudio igualmente se induce lo que estaba presente en la mirada de los participantes a través de lo visto y no visto en la arquitectura de la ciudad (Burke, 2001). Esta situación, permite comprender aspectos que hicieron parte de los mapas culturales y de los imaginarios de observación que este grupo de trabajo hizo, visibles en las categorías de análisis que conformaron las fichas y de su prevalencia en: ambientales, técnicas, documentales, artísticas e históricas y en menor medida paisajísticas. El es-

Pensamiento Americano Vol. 14 - No. 27 - p.p. 181-194 • 2021 • Enero - Junio · Corporación Universitaria Americana • Barranquilla, Colombia • ISSN-e: 2745-1402 http://publicaciones.americana.edu.co/index.php/pensamientoamericano/index 


\section{Figura 1.}

Sintesis estructura formal Arquitectura Tunja.

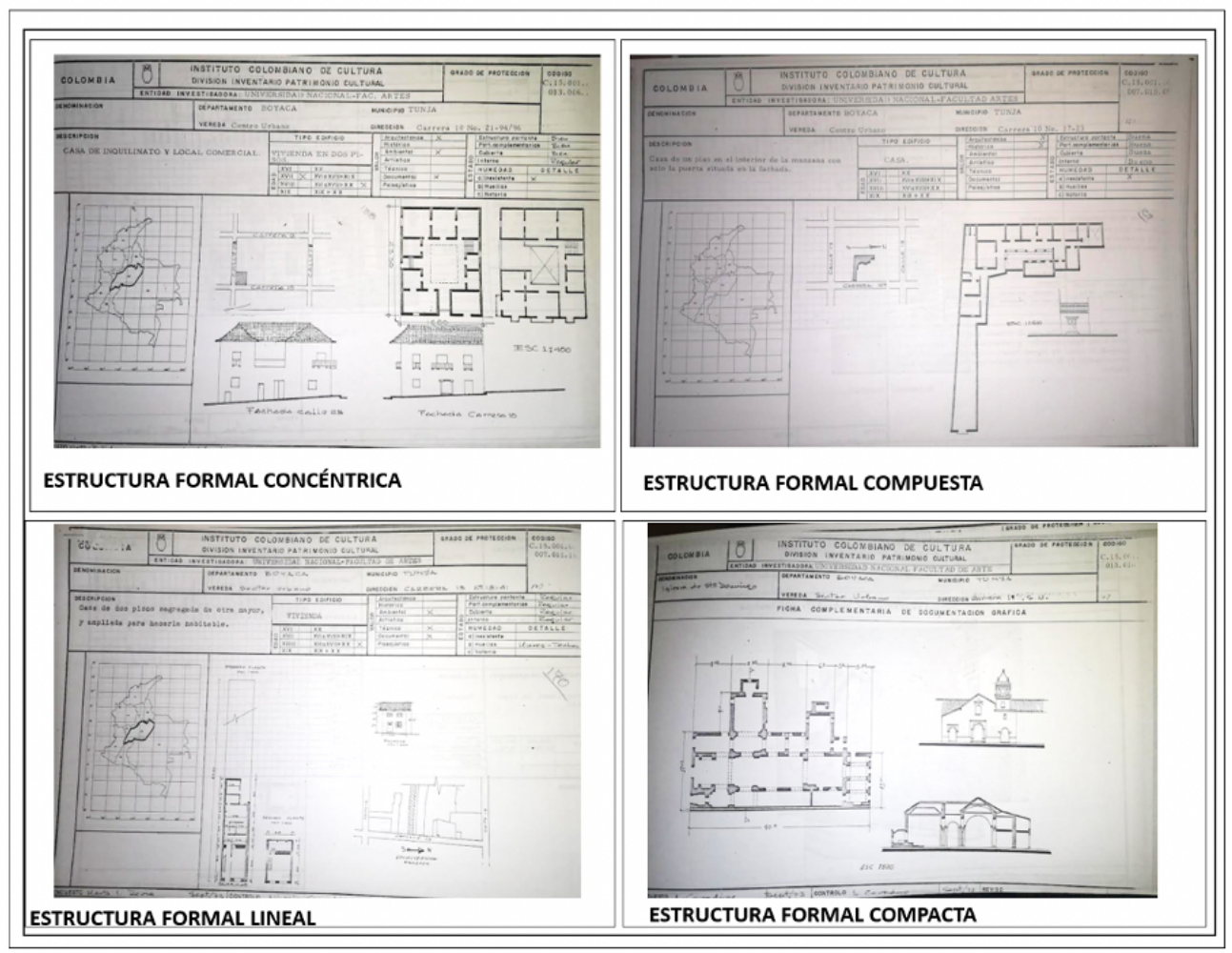

Fuente: Corradine (1973).

tudio de esta documentación y su sistematización, permite concluir igualmente en su grado de persistencia, particularidades constructivas visibles en el uso de la tapia pisada, el adobe, la madera y la teja de barro, como valores identitarios de la arquitectura heredada del espacio urbano Colonial de Tunja.

De otra parte, para 1977 en el trabajo Conservación del centro histórico de Jorge Ayala Coll (1977), adelantado bajo la dirección de Jaime Salcedo, se expresó un cuadro patrimonial que hizo énfasis en el desarrollo de la morfología urbana a través de períodos diferenciados de tiempo, representado en el título "planos evolutivos de la ciudad de Tunja" (Coll, 1977, p. 12), y que interpretó un desarrollo urbano menor de 1623 a 1939, y el cual para 1971 presentó la siguiente descripción:

Es notorio el crecimiento de la ciudad con relación al año de 1965, hacia todos sus lados la ciudad tuvo crecimiento, reflejado por el número de barrios y calles nuevas que rodean el casco antiguo de la ciudad. A pesar del crecimiento violento de la ciudad en los últimos años. Se puede concluir que Tunja ha sido de crecimiento lento ya que no ha logrado vencer prácticamente su esquema inicial hasta los momentos y se encuentra todavía en esa lucha para lograrlo. (Ayala, 1977, p. 14).

En esta descripción de la ciudad, igualmente resaltó la incidencia de la corriente progresista denunciando casos alarmantes de pérdida del patrimonio, en el costado sur de la plaza de Bolívar y del edificio del centro Cívico, ubicado sobre el antiguo claustro de San Francisco, según se presenta a continuación:

Por último, tenemos a las construcciones del siglo $\mathrm{XX}$, se nota una fuerte infiltración de este periodo dentro del centro, originado principalmente por la corriente "progresista" que domina y que se encuentra acabando a lo poco que le han dejado, Como los casos más alarmantes en este sentido se 
pueden mencionar, en primer lugar, el costado Sur de la Plaza de Bolívar que fue destruido para hacer unos edificios "dignos" de la ciudad y que además de cometer semejante crimen no respetaron la volumetría existente y afectaron por completo la relación de espacios que se guardaba anteriormente en ella. Otro ejemplo que es de los que más afecta a la ciudad es el edificio del Centro Cívico, primero por haber demolido al claustro de San Francisco. Lo cual no tiene justificación ya que podía ser conservable y por ende buscar otra localización, que la hay, en la ciudad para la elaboración de dicho proyecto; segundo, hacen un "monstruo" que tampoco guarda ninguna relación espacial ni volumétrica con sus alrededores, además de considerarlo, en cuanto a su programa fuera de escala en las necesidades de la ciudad; y así hay muchos ejemplos más en el centro. (Ayala, 1977, p. 16)

De esta manera, el impacto de nuevas construcciones en el espacio urbano heredado fue una situación visible en diferentes percepciones narradas sobre la ciudad y cuya corroboración se sigue en la siguiente representación visual (Figura 2), testimonio visual de la expresión de una nueva arquitectura que se caracterizó por presentar en la verticalidad y en la imposición de una masa autorreferencial soportada por la rentabilidad del espacio habitable; los signos de nuevos principios de organización espacial diferentes a los presentes en el espacio urbano heredado de siglos anteriores:

\section{Figura 2.}

Plaza principal de Tunja

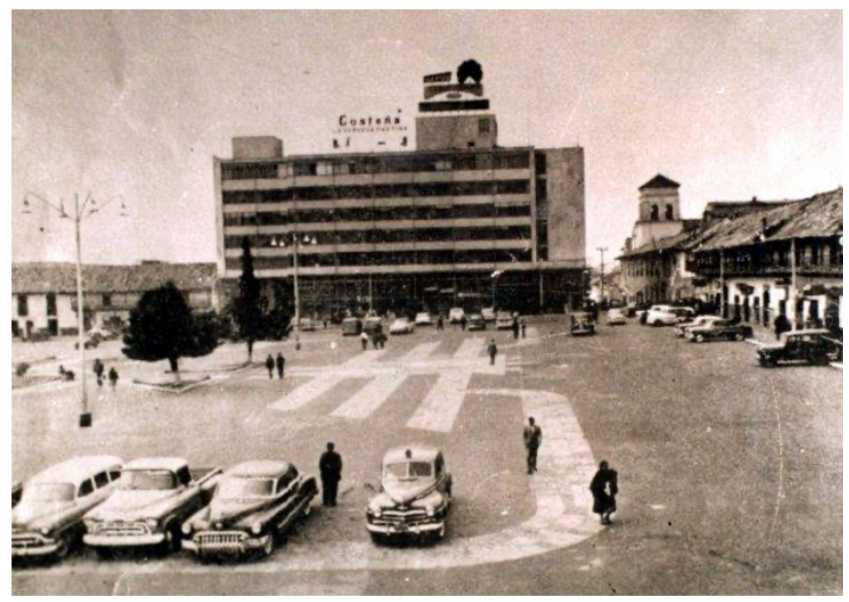

Fuente: Archivo Foto Veracruz, Tunja, (1960)
$\mathrm{Al}$ triangular, este cuadro de percepciones en el espacio, este estudio ha permitido establecer una síntesis gráfica que expresa dos aspectos de trabajo a saber: el relacionado con los valores históricos que conformaban el ideario de sitios de interés para finales de 1970, así como las principales características del espacio urbano, que se caracterizaron por la convergencia de un sentido de usos y la divergencia de sus soluciones formales, siendo este un rasgo característico en el sector antiguo de Tunja durante la segunda mitad del siglo XX así:

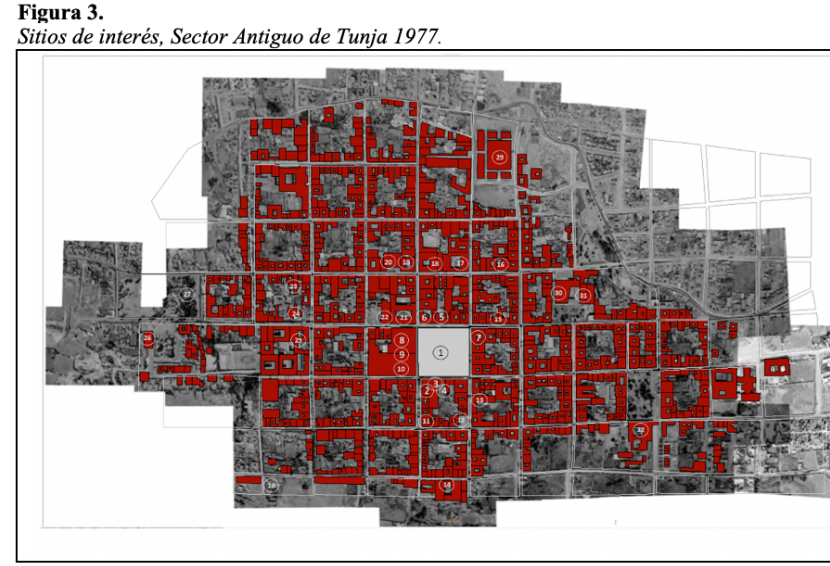

Fuente: Corradine. (1977)

1. PLAZA DE BOLIVAR

2. LA IGLESIA CATEDRAL

3. LAATARAZANA

4. CASA DE SUAREZ RENDON

5. (FUNDADOR)

6. COSTADO OCCIDENTAL PLAZA

7. CASA DE LA CULTURA

8. CASA DE LA TORRE (GOBERNACIÓN).

9. EDIFICIO ALCALDÍA Y PLANEACIÓN

10. EDIFICIO DE CATASTRO AGUSTÍN CODAZZI

11. EDIFICIO TELECOM

12. CASA DE DON JUAN DE CASTELLANOS

13. MONO DE LA PILA

14. CASA DEL ESCRIBANO DEL REY JUAN DE VARGAS

15. CLAUSTRO DE SANTA CLARA LA REAL

16. CASA DE MIGUEL HOLGUÍN Y MALDONADO CLUB BOYACÁ.

17. CASA DE BERNARDINO DE MOJICA Y GUEVARA

Pensamiento Americano Vol. 14 - No. 27 - p.p. 181-194 • 2021 • Enero - Junio · Corporación Universitaria Americana · Barranquilla, Colombia • ISSN-e: 2745 -1402 http://publicaciones.americana.edu.co/index.php/pensamientoamericano/index 


\section{IGLESIA DE SANTO DOMINGO \\ 19. CASA DE ANTONIO RUIZ MANCIPE \\ 20. CENTRO BANCARIO \\ 21. COLEGIO DE BOYACA \\ 22. IGLESIA DE SAN IGNACIO \\ 23. IGLESIA DE SANTA BÁRBARA \\ 24. HOTEL CENTENARIO \\ 25. CASA DE LA CURIA \\ 26. IGLESIA DE SAN LAUREANO \\ 27. PARQUE PAREDÓN DE LOS MÁRTIRES \\ 28. TERMINAL DE BUSES \\ 29. PLAZA DE MERCADO \\ 30. CENTRO CÍVICO \\ 31. IGLESIA DE SAN FRANCISCO \\ 32. CLAUSTRO Y CAPILLA SAN AGUSTÍN \\ 33. HOSPITAL}

Basado en la reconstrucción de Monumentos Históricos y sitios de referencia, que se desprende de los documentos de estudio; se hace visible en la figura (03), que, a finales de la década de 1970, resaltaba la falta de distinción que se hiciera en su momento entre monumentos religiosos y de arquitectura doméstica, situación que da cuenta de su percepción como una unidad construida. Igualmente es significativa la presencia de las intervenciones que se hicieron en la primera mitad del siglo XX, expresadas en el Parque Paredón de los Mártires (2), la plaza de mercado (29). Adicionalmente, sobresalía el centro Bancario de la ciudad (20), que se adelantó sobre edificaciones de tipo colonial y de las cuales no quedó ningún registro, así como el llamado edificio CAMOL, (figura 04), que se adelantó arrasando con la arquitectura colonial de una vivienda edificada, además del centro Cívico de la ciudad.

El estudio de otras fuentes de archivo permite concluir otro aspecto del espacio urbano representado de la década de 1970 a saber: el relacionado con el ideario de planificación que vivió Tunja en la segunda mitad del siglo XX, con la implementación del plan piloto de 1958 y los planes de desarrollo de 1973 - 1978. En efecto, los modelos de planeación que surgieron desde 1975 como actualización del Plan
Piloto de 1958, se constituyeron en la génesis de la planeación que se instauró en la ciudad después de 1980, cuya principal característica fue una presión utilitaria y de rentabilización del espacio, y con ello una situación de acondicionamiento tipológico al interior de la arquitectura doméstica de este sector de la ciudad; expresiones que surgen, como claves de lectura para comprender las características del espacio urbano del sector histórico de la ciudad y cuya síntesis se presenta:

Figura 4.

Sintesis Espacio Urbano Sector Antiguo de Tunja 1977.

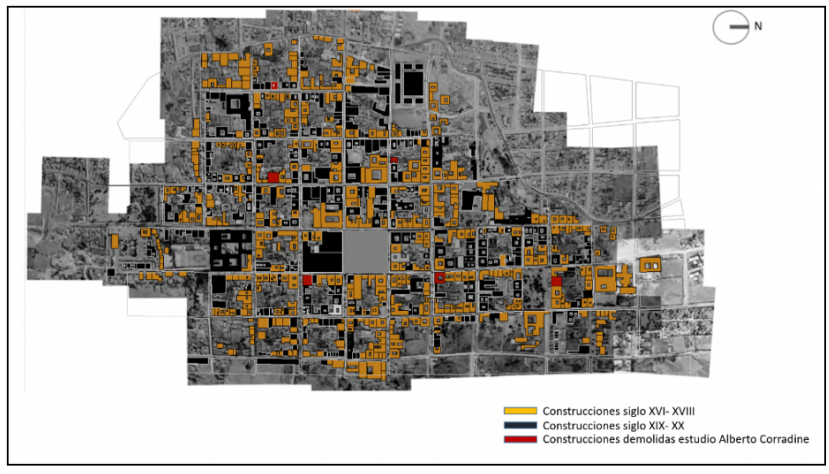

Fuente: Corradine (1977).

En este sentido, la síntesis de cambios de la figura (04), permite concluir que los paisajes urbanos presentes a inicios de la década de 1950, caracterizados por la prevalencia de edificaciones coloniales; para 1978, contrastaba con los nuevos desarrollos de diferentes edificaciones de arquitectura popular provenientes del siglo XX, con una transformación significativa del paisaje urbano Colonial. En este paisaje urbano polivalente, nuevas edificaciones albergan usos específicos en número así: "tres bibliotecas, veintitrés restaurantes, cinco clubes sociales privados y cuatro salas de cine con el cinema Boyacá, Quiminza, y Suárez Rendón” (DANE, 1985, p. 97). Esta situación expresa una nueva arquitectura en la ciudad que respondía a lógicas diferentes a las que habían motivado la construcción de la ciudad colonial. A su vez, nuevos edificios para oficinas y entidades bancarias complementaban este conjunto moderno: el edificio Camargo Molina CAMOL, adelantado desde 1968, el edificio Hotel Hunza; (Figura 05), así como la edificación para las nuevas oficinas 
de la cámara de comercio sobre la calle 21 y carrera 10 , que se adelantaron posteriormente, constituyeron eventos sin precedentes que modificarían la silueta urbana de la ciudad Colonial.

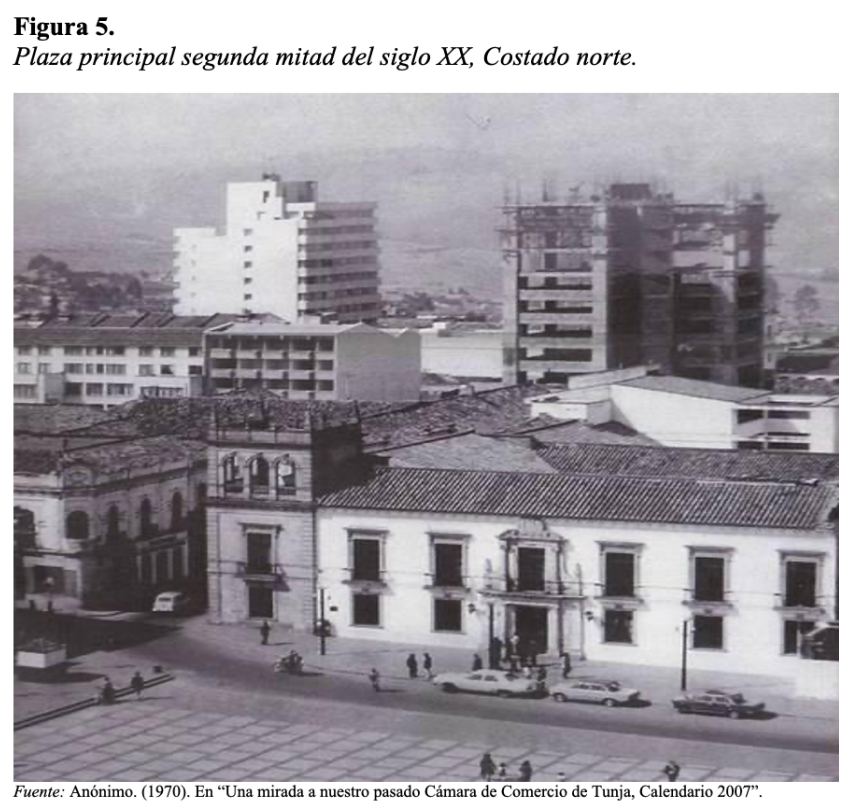

En suma, se puede determinar, al revisar la ubicación de estos predios con sus cambios y prevalencias, que durante la década de 1970, en el sector antiguo de Tunja, los imaginarios urbanos, tuvieron unas representaciones culturales y materiales caracterizadas por un sentido de pérdida y alarma frente a los estragos de una arquitectura que no guardó relación con el espacio urbano heredado y desconfigura su esencia y homogeneidad, siendo esta la principal síntesis visual heredada que ha llegado al presente, ejemplo de las complejidades que vivió el espacio urbano heredado de la ciudad colonial en el contexto latinoamericano.

\section{Marco teórico}

En el contexto de estudios que han centrado su 190 atención en la ciudad y sus significados históricos y culturales, han sido textos instauradores: muerte y vida de las grandes ciudades de Jane Jacobs (1973), el mundo como representación de Roger Chartier (1983) y la imagen de la ciudad de Kevin Linch (1984), estudios que conceptualizan a la ciudad des- de sus representaciones, aspectos y sus siluetas urbanas. Estos trabajos, en Colombia motivaron una línea de reflexión con títulos canónicos como: imaginarios urbanos, cultura y comunicación urbana de Armando Silva (1992) así como los títulos del arquitecto e historiador Juan Carlos Pergolis (1998): Bogotá fragmentada, estación Plaza de Bolívar (2000) y más recientemente el título imaginarios y representaciones, Bogotá 1950 - 2000 Forma urbana y vida cotidiana (Pergolis \& Rodríguez, 2016). En estos trabajos, los autores transportan al lector por el universo de los significados y las representaciones, visibles en sus expresiones, de una vida cotidiana que da sentido al espacio urbano y con ello al ser urbano en el contexto latinoamericano.

En este contexto, este escrito se concibe dentro de este ambiente y perspectiva de la ciudad, haciendo énfasis en sus significados y particularizando su estudio, desde su historia. Para lograrlo, la ciudad es asumida como "- un nudo - de relaciones sociales, que al especializarse da forma a un lugar humanamente construido", (Mejía, 2012, p.16) y a su vez, como: "una manifestación, de gran complejidad espacial y social” (Almandoz, 2008, p. 28) y cuyo estudio en el tiempo y en un espacio determinado permite su conocimiento a través de la historia urbana y cultural. A su vez, su lectura se hace con el análisis de los imaginarios urbanos que la representan, entendidos como: "una construcción social de imágenes de la ciudad, resultado de las percepciones que sus habitantes tienen de ella" (Pergolis \& Rodríguez, 2019, p. 9), y cuyo significado se asume al entender la ciudad como: un tejido comunicacional, como fragmentos de espacio y de comportamiento que crean pliegues culturales sobre una estructura leve, ligera, homogénea y sin jerarquías” (Pergolis, 2000, p. 22).

\section{OBJETIVOS}

\section{El desarrollo de esta reflexión presenta como} objetivo central de trabajo, cuestionar la categoría de los imaginarios urbanos y representaciones culturales y determinar su incidencia como medio de análisis en la historia del Sector Antiguo de Tunja 
en los años comprendidos entre 1968 y 1979. De esta manera, los objetivos específicos de trabajo proponen determinar los hechos históricos presentes en la arquitectura y el urbanismo y fuentes históricas primarias y secundarias, que representan los cambios y prevalencias del sector antiguo de Tunja en el periodo comprendido entre 1968 y 1979; caracterizar los factores diacrónicos y sincrónicos que permiten particularizar los imaginarios urbanos y representaciones culturales en el espacio urbano heredado del sector antiguo de Tunja en el periodo objeto de estudio; establecer las categorías históricas de significación, que permiten comprender las correlaciones entre actores y fuerzas urbanas, los imaginarios urbanos y representaciones de actores culturales y académicos y su representación en las representaciones del espacio urbano heredado de este sector de la ciudad.

\section{METODOLOGÍA}

Metodológicamente, el estudio ha centrado su atención en los imaginarios urbanos y representaciones culturales del sector antiguo de la ciudad (1968 - 1979). Su desarrollo se adelantó bajo un enfoque cualitativo e inductivo que propuso en primer lugar, el conocimiento de fuentes de archivo, de imágenes fotográficas y de relatos descriptivos y textos historiográficos que permiten comprender el tema desde el ámbito local de la ciudad, y de aquellos que surgieron en el contexto latinoamericano, para establecer las percepciones, los sentidos de la representación, así como las características de las imágenes que las soportaban, y con ello determinar sus tendencias como parte de la historia urbana y cultural de la ciudad en el periodo objeto de estudio. En segundo lugar, se hizo una sistematización y problematización de las fuentes primarias y de archivo, así como de fuentes historiográficas, reconociendo sus convergencias y divergencias, así como sus principales categorías de interpretación, las cuales permitieron determinar las siguientes tendencias de estudio: modernización y estética de la ciudad heredada, la nueva arquitectura y urbanismo, representaciones del espacio urbano heredado presente en la ciudad, y finalmente la reglamentación urbana y arquitectónica que caracterizó a la ciudad antigua y a sus significados sociales. Finalmente, se hizo una síntesis interpretativa que permitió determinar las características de los imaginarios urbanos y representaciones sociales, presentes en el sector antiguo de la ciudad y establecer sus repercusiones en el desarrollo urbano y sentido de conservación del patrimonio urbano del sector antiguo de Tunja, en el contexto latinoamericano.

Las fuentes de información se trabajaron en: el Archivo Histórico Regional de Boyacá, Archivo Municipal de Tunja, el archivo del Concejo Municipal, la Biblioteca de la facultad de Artes de la Universidad Nacional de Colombia y la red de Bibliotecas del Banco de la Republica en Colombia. Por su parte se hizo una contextualización de los temas en los centros de documentación y Bibliotecas del Colegio de México, del Instituto Mora, de la Dirección de estudios Históricos del INAH, en México; y la Biblioteca de la Universidad Nacional de Rosario en Argentina, principalmente.

\section{CONCLUSIONES}

Esta reflexión, que ha versado sobre la incidencia de los imaginarios urbanos y representaciones culturales en la historia del sector antiguo de Tunja entre 1968 y 1979, ha permitido comprender que estas perspectivas de acercamiento para el conocimiento de la historia urbana es un camino viable, como medio de análisis y comprensión de la ciudad. En efecto, en este estudio de caso se ha podido constatar, que se pueden comprender los factores culturales que han incidido en la historia urbana de una ciudad a partir del análisis de diferentes imágenes y narrativas que se han elaborado sobre el espacio urbano heredado, como fuente de conocimiento singular.

En este sentido se determinó igualmente, que estas perspectivas de trabajo son una oportunidad en el campo de los estudios sociales y de la historia urbana, que nutren la indagación por comprender los fenómenos sociales y las representaciones histó-

Pensamiento Americano Vol. 14 - No. 27 - p.p. 181-194 • 2021 • Enero - Junio • Corporación Universitaria Americana • Barranquilla, Colombia • ISSN-e: 2745-1402 http://publicaciones.americana.edu.co/index.php/pensamientoamericano/index 
ricas y culturales, a partir del estudio de diferentes fuentes que contienen percepciones sobre la naturaleza del objeto de estudio que en esta oportunidad fue el espacio urbano del sector antiguo de Tunja en el periodo objeto de estudio. El estudio de cartografías, fotografías y narrativas sobre el sector antiguo de Tunja, han sido fuentes de información determinante para logra este cometido. De esta manera, es plausible pensar que la ciudad como objeto de indagación del pasado y del análisis de sus significados en el tiempo, permite hacer énfasis en los signos del lugar; con lo cual, se aportan elementos para la comprensión de los ambientes de discusión, con sus intereses, preocupaciones y anhelos, como aspectos de la historia que deben ser puestos en consideración.

Como sustrato conceptual, igualmente significativo es entender que el acercamiento metodológico a los estudios históricos de la ciudad desde una perspectiva inductiva, permite fijar la atención en las tendencias, prevalencias y ritmos de cambio presentes en las fuentes testimoniales y en la historiografía, que ambientan las discusiones que van surgiendo sobre las representaciones y experiencias relacionadas con el objeto de estudio de la ciudad, permiten centrar la atención en los fenómenos, en su identificación y en el establecimiento de líneas de trabajo que aportan a la narrativa histórica sobre la ciudad. Con relación al sector antiguo de Tunja, las posturas que surgieron en torno a la forma urbana y las tipologías arquitectónicas fueron determinantes para la comprensión de las características de un patrimonio urbano heredado, que se caracterizó por estar en un estado de amenaza y sobre el cual las recomendaciones y acciones de denuncia para su conservación fueron una constante que se siguió en todo el periodo de estudio.

De esta manera, como resultados de esta reflexión, se destacan los contextos e idearios de un grupo de académicos que tuvieron como fin, asumir una postura decidida frente a la pérdida de expresiones monumentales, históricas y culturales en la ciudad. En el ambiente de la ciudad este fue un rasgo característico de este periodo de tiempo; en el cual se identificó una percepción sobre la pérdida de significación del espa- cio urbano heredado y una indiferencia inmobiliaria frente a su importancia como portador de la memoria histórica e identitaria de la ciudad.

Por su parte, en el contexto latinoamericano se pudo comprender que la década de 1960, fue un periodo caracterizado por un ambiente de pensamiento, que se caracterizó por la búsqueda de una identidad latinoamericana a través del estudio de sus ciudades tal como sucedió en la ciudad de Tunja. Aún más, el estudio de los relatos de los académicos que se tomaron como referente en este estudio, ha permitido concluir que esta preocupación hizo parte de los intereses para el estudio de la ciudad y que los títulos y documentos técnicos elaborados, fueron un medio para dar a conocer la ciudad, con sus valores históricos, artísticos y culturales, en un medio de pérdida y de cambio urbano.

En este sentido, el estudio de los relatos y las representaciones gráficas que surgieron con planimetrías de la ciudad y de la arquitectura, expresaron una percepción de la ciudad que se caracterizó por un sentido de añoranza sobre la composición del espacio urbano heredado del siglo XVI. A su vez la denuncia de un movimiento progresista que impuso sobre el sector antiguo de la ciudad sus realizaciones bajo nuevos cánones de composición que contrastaron con el ideario homogéneo del orden colonial, es un hecho determinante para conocer los contextos de estas discusiones y reflexiones sobre la ciudad.

De igual manera es importante recalcar, el papel que tuvo en el ideario representado en estos estudios, los sitios de interés representativos de la ciudad, que se caracterizaron por la persistencia de imaginarios urbanos y representaciones sociales constituidas por diferentes representaciones heredadas del orden colonial, republicano y del nuevo estado nacional, bajo una identidad progresista que incidió de manera radical frente a las expresiones anteriores que conforman el patrimonio urbano de la ciudad.

Finalmente, la recomposición y la constitución

Pensamiento Americano Vol. 14 - No. 27 - p.p. 181-194 • 2021 • Enero - Junio • Corporación Universitaria Americana · Barranquilla, Colombia · ISSN-e: 2745-1402 http://publicaciones.americana.edu.co/index.php/pensamientoamericano/index 
de una síntesis de todos los hechos que caracterizaron la historia urbana del sector antiguo de la ciudad en el tiempo objeto de estudio, se constituye en una oportunidad para diagramar y adelantar explicaciones visuales, que vinculen fuerzas urbanos, actores sociales y grupos culturales como parte de la explicación, que permitan comprender a través de las representaciones de la arquitectura y el urbanismo la síntesis de una ciudad viva con conflictos internos y anhelos urbanos, que permitan una comprensión de la dimensión espacial de la ciudad en el tiempo, sus contextos y sus principales características, con lo cual se hace un aporte a este tipo de estudios que tienen por objetivo final reflexionar sobre nuestra historia desde una visión de contexto y de las circunstancias que incidieron en la visión que tenemos de nuestro presente a la luz del cuestionamiento constante al pasado.

\section{Referencias}

Almandoz, A. (2008). Entre libros de historia urbana para una historiografía de la ciudad y el urbanismo. Ed. Equinoccio.

Ayala Coll, J. (1977). Conservación del centro histórico. Instituto de investigaciones

Bonta, J. (1973). Notas para una teoría del significado del diseño. Versus 6(2).

Burke, P. (2001). Visto y no visto. El uso de la imagen como documento histórico. Biblioteca de bolsillo.

Carrión, F. (2019). El Centro Histórico objeto de estudio e intervención. Editorial Pontificia Universidad Javeriana. Colección Biblioteca Profesional.

Carta de Atenas (1933). La Carta De Atenas. París: IV Congreso de Arquitectura Moderna [CIAM].

Carta de Washington. (1987). Carta internacional para la conservación de ciudades históricas y áreas urbanas históricas. https://legislaciondelpatrimoniocr2017.blogspot. com/2017/05/carta-de-1987-de-la-conservacion-y.html

Chartier, R. (1983). El mundo como representación. Historia cultural: entre práctica y representación. Gedisa Editorial.

Comité Internacional de la Cruz Roja. (1954, 14 de mayo). Convención para la Protección de los Bienes Culturales en caso de Conflicto Armado y Reglamento para la aplicación de la Convención 1954. https://www.icrc.org/es/doc/resources/ documents/misc/treaty-1954-hague-convention-cultural-property-5tdm2q.htm

Corradine, A. (1973). Inventario de bienes históricos de Tunja. Instituto colombiano de Cultura. Colombia: División inventario de patrimonio cultural Universidad Nacional de Colombia Facultad de Bellas artes.

DANE. (1985). Monografía del municipio de Tunja. Tunja: Coordinación editorial Dirección General de información Técnica y regional Central DANE. 
Gutiérrez, R. (1984). Arquitectura y urbanismo en Iberoamérica. Ed. Manuales Arte Cátedra.

Hardoy, J. (1964). Ciudades precolombinas. Ediciones Infinito.

Hardoy, J. (1974). El proceso de urbanización en América latina. Oficina Regional de Cultura para América Latina y el Caribe, Centro de Documentación.

ICOMOS. (1964). Carta de Venecia. Venecia: II Congreso Internacional de Arquitectos y Técnicos de Monumentos Históricos.

Jacobs J. (1973). Muerte y vida de las grandes ciudades. Capitán Swing Libros.

Linch, K. (1984). La imagen de la ciudad. Ed. Gustavo Gili.

Mejía, G. (2012). Los años del cambio Historia Urbana de Bogotá 1819-1910. Ed. Ceja.

Pergolis, J. \& Rodríguez, C. (2016). Imaginarios Urbanos y representaciones, Bogotá 1950 - 2000, Forma Urbana y vida cotidiana. Editorial Universidad Católica de Colombia.

Pergolis, J. (1998). Bogotá fragmentada. Cultura y espacio urbano a finales del siglo XX. TM editores. Universidad Piloto de Colombia.

Pergolis, J. (2000). Estación Plaza de bolívar. Alcaldía Mayor de Bogotá,

Romero, J. (1975). Latinoamérica. Las ciudades y las ideas. Ed. Siglo XXI, Editores S.A.

Sebastián, S. (1966). La Ornamentación Arquitectónica en la Nueva Granada. Divulgación Cultural de Boyacá. Galería de Autores Boyacenses.

Segre, R. (1975). América Latina en su Arquitectura. Ed. Siglo XXI.

Silva, A. (1992). Imaginarios urbanos, cultura y comunicación urbana. Ed. Tercer Mundo Editores.

2021, Vol. 14(27) -191-194. CThe Author(s) 2021

Reprints and permission: www.americana.edu.co

http://publicaciones.americana.edu.co/index.php/pensamientoamericano/index

Pensamiento Americano Vol. 14 - No. 27 - p.p. 181-194 • 2021 • Enero - Junio · Corporación Universitaria Americana · Barranquilla, Colombia • ISSN-e: 2745 -1402 http://publicaciones.americana.edu.co/index.php/pensamientoamericano/index 